\title{
Impact of CNG Load Shedding on Daily Routine: A Study of Pakistan
}

\author{
Muhammad Arslan ${ }^{1, *}$, Rashid Zaman ${ }^{1}$, R. K. Malik ${ }^{2}$ \\ ${ }^{1}$ Bahria University, PO box 440000, E-8, Islamabad, Pakistan \\ *Tel: 00923317500173 \\ ${ }^{2}$ Head of Campus, Shaheed Zulfiqar Ali Bhutto, Institute of Science and Technology, \\ Islamabad, Pakistan \\ *E-mail address: MuhammadArslan73@gmail.com
}

\begin{abstract}
People of Pakistan are facing a number of problems due to CNG load shedding. This study investigated the consequences of energy on routines of people and also on social and economic performance of people. Primary data has been collected by conducting video recorded interviews and comment based interviews from twin cities i.e. Islamabad and Rawalpindi of Pakistan. The sample of study includes students, housewives, businessmen and professional workers who are affecting by this CNG shortage. This study focuses on relationship between CNG shortage and its effect on daily routine life and performance of people. It also focuses on psychological issues as well as the economic issues that are caused due to this shortage. This study utilizes in depth semi structured interviews to conduct the qualitative study. N-Vivo 10 is used as tool of data analysis. The CNG shortage in Pakistan caused many critical issues like unemployment, decrease in export contracts and commodities prices are increasing due to this shortage. Less working hours, lack of social and family gathering, increase in work load, depression and anxiety are results caused by CNG shortage. It is concluded that CNG shortage has bad impact on people's lives and on their overall performance.
\end{abstract}

Keywords: Pakistan; CNG Shortage; Energy; N-Vivo; Commodities

\section{INTRODUCTION}

\section{1. Background of Study}

The price of international trade oil that took place during the last three or four decade gave ascend to prevalent problems of economic and energy adjustments throughout the world. The beneficiaries of this rise in prices of oil are oil exporting countries. The demand of energy also plays crucial role in changing the energy prices. The coupling of economic system and energy system led to increase in inflation and almost every aspect which was related with energy has affected tremendously. Energy means ability to do work. Shrinkage in existing resources, recent rise in energy prices and energy conservation technologies have brought the importance of energy use and economic growth in focus. The input of energy to the output of industrialized countries is a divisive topic in economic theory. The initial works of some authors left no room for doubt about the importance of the energy factor in productivity (Rosenberg, 1983; Schurr, 1983). 
Energy is the major and most critical input of any production activity. Expansion in energy and its resources can lead to higher growth and shortage of this energy may lead to shrink in growth. Over the last three or four decades the overall world economy has bearded many swings in energy prices. These swings have very upshot for under developed countries of Asia and also on other countries. Many researches showed that, after a decade of oil worries, consumers and their government should also find delight in today's oil market (Gravin, 1983).

In small countries like Belgium which are suffering with declining coal industry and Denmark with its scarce energy output, have responded to transformation of world energy economy over the last one decade (Michael, 1986). Like other countries California has been tormenting scarcity of resources through the nineteenth century (James, 1996). The resources of coal have proved as lower quality. The wood was depleted due to convenience of urban areas. In early 1970s the economies of Western Europe had become heavily dependent upon imported oil. The OPEC induced price rises from two to thirty dollars per barrel between 1972 and early 1980s. In Bangladesh, about three to fourth of total consumption of primary source of energy is from the firewood and crop residues.

If the swiftly growing economies of Pakistan, India and China don't plan then it can face severe energy crisis. Few researches also showed that China is in the process of industrialization and electricity is pre-requisite for rapid growth. At the same time, the "coalbased" energy structure in China will not change perennially, which means, the enlargement of power industry will be focus theme to the constraints of resources and environment for a long period of time. Therefore, according to the development of electric power industry, energy saving and emission reduction will be an endless theme (Kou, 2009).

Findings of some researchers showed that there was positive relationship between consumption of energy and exports of country. It has also other effect on other hand because if the exports increased, it increased the level of energy consumption (Li, 2010). Eleventh five year report of India showed that India was major consumer of energy. India also has world ranking in energy producing, it has seventh rank. The $2.49 \%$ of total annual energy production was from India ("Eleventh Five Year Plan," 2010). Some authors employed an integrated assessment in an effort to compare the effectiveness of prospective policy options to tackle a range of energy and an environmental issue which couples a technology-rich bottom-up model of the U.S. electricity sector with a fully dynamic forward-looking general equilibrium model of the U.S. economy. The model provided a distinctive and steady modeling framework for energy and environmental policy analysis. Though energy efficiency standards are found to be the least cost-effective at reducing energy usage or mitigating carbon emissions, their appeal is likely to rest on assumptions about specific market failures or on political factors (Yuan, 2010).

Currently, Pakistan has been suffering energy shortage due to inappropriate decision making, incapability of government and deteriorated laws. As a result, whole economy is suffering i.e. industry, commercial exports, domestic life and local businesses of Pakistan. The problem has not been addressed yet and it is becoming challenging for any government to fulfill the energy demand in near future. From last one decade people of Pakistan were tormenting from electricity shortfall but due to inappropriate policies, people are now besieged for gas shortages as well. Amplified use of enhanced energy sources helps people in humanizing the quality of life, saves time and environment. This usage of energy also humanized the delivery of social services. The easy availability of better quality fuel improves the lives of females and children who used traditional method of fuel like gathering of wood. In Pakistan, gas is the one of the most important source of energy. Pakistan is the world 
largest user of gas as fuel in public and private transport with 2.5 million vehicles (Zaid, 2012).

As compared with prices of other sources of fuel like petrol, the price of gas was half. There was found burgeon growth of CNG stations throughout the country especially in Punjab region. Although the government is now annoying to reduce the gap between gas and petrol prices but government is incapable to meet the demand of gas for industry. Countless industries are being shut due to gas shortage. This shortage forced a number of textile units to close down due to delay in fulfillment of their export consignments (Jamal, 2012). Some studies showed that lack of integrated planning, non-utilization of local resources and imbalanced energy mix were major causes of energy crisis in Pakistan (Ahmad, 2009).

Now in current situation it has become a serious matter of daily routine life due to unannounced CNG load shedding and low pressure of gas. Moreover, it has also been reported that in many small cities and towns of Pakistan, the commodity continues to disappear for many hours before any prior information of this load shedding. Thus the public and private transport is affecting and ultimately domestic users, professionals and students are also. All Pakistan CNG Association (APCNGA) on 5 January 2011, staged a protest demonstration and sit in against the prolonged and unannounced gas load shedding in front of parliament. Transport unions of twin cities of Islamabad and Rawalpindi also participated in this sit in. The protesters demanded that government should exempt the CNG sector from gas load shedding because most of the transport was running on CNG (APA, 1995).

This qualitative investigates the problems and issues that arise from this unannounced close down of CNG stations and CNG shortage. This study also determines the effect of these energy crises on daily routine life of people. These issues include daily routine life factors which are affecting from this shortage. Psychological and social issues are also investigated in this study. Due to critical relationship of energy and growth of economy, issues that can affect the economic situation of country are also addressed in this study.

\section{METHODOLOGY}

\section{1. Research Design}

The research design of this qualitative study was iterative. It means research questions are adjusted to what is learned from respondent. In this research design there is effect of participant responses, how and which question researcher would ask to next (Field Guide). Research design must be responsive with the context (Richards, 2006).

\section{2. Sample}

In this study the purposeful convenient sampling technique was used. This technique was useful when data was collected from those respondents which gave you in-depth and relevant data (Harms, Jack, Ssebunnya, \& Kizza, 2010). The sample of this study includes daily users of transport that are running on CNG. The sample size in this study was 30 respondents. These respondents included students, house wives, businessman and drivers of public transports. 


\section{3. Context}

The context of this study was the providers of compressed natural gas (CNG) located in territory of Islamabad. These included the crowded CNG stations in the twin cities of Pakistan.

\section{4. Collection of Data}

In this study the video recorded semi- structured interviews were conducted for data collection. This method is optimal when you want to get in depth information about an issue. In-depth interviews are less structured than semi-structured ones and may cover only one or two issues. This type of interview is used to explore in detail the respondent's own perceptions and accounts. Interviews were started by some open questions and then some questions related to topic or issue that was under investigation. The qualitative interviews were scheduled at that time when users of $\mathrm{CNG}$ were waiting for their turns to fill tank for many hours. Each interview lasted from 10-15 minutes.

\section{5. Data Analysis}

The computer software QSR NVIVO 10 was used as tool for analysis of data. In NVIVO, all data were imported then transcribed data into textual form for analysis. After transcribing data, explored the themes and code them. For the coding of date, auto coding method was used and then converted this data into nodes. After it classification of data, Queries were run for generating the word frequency and tree map of data. At the end, model of study was generated by selecting all themes which were coded into nodes. There was used content analysis due to exploring nature of study. After applying the analysis these results were exported to some other destination and saved them.

\section{RESULTS}

\section{1. Word Frequency of Study}

The Figure 1 showed the word frequency of present study in graphical form. In the Figure 1 there was shown the weight-age percentage of word that was used frequently. There was also shown the count of repeated words and also the length of the frequently used words, it could be seen that the word CNG was repeated about 133 times in this study. The word transportation was repeated 25 times in this study. The word routine, useless, difficulty and earnings were repeated 20 times in this study. This study consisted of 30 respondents but the frequency of words was more than the respondents. It meant that some respondents used these words more than one time. From the above figure it could be interpret that CNG shortage had been created a lot of problems and it has affected their routine life tremendously.

\section{2. Text Query}

Figure 2 showed that due to this unannounced and shortage the efficiency and productivity level of employees, students and households are decreasing day by day. Due to this energy crisis there were increasing complaints for low level of performance.

Figure 3 shows the impact of CNG shortage and its impact on working and studying life of employees and students. Due to this draw back the work load has increased many folds and studying hours of students has been affected immensely. Wastage of time has been increased. 
In Figure 4, there were many psychological issues which are flourishing due to CNG shortage. These factors included tension, stress, depression and anxiety. These factors have been affecting life of and have bad impact on their health.

\section{3. Tree Map of study}

The Figure 5 shows the tree map of CNG load shedding and its impact on daily routine life of people. A tree map was that which shows the cause and effect relationship of something. In above tree map there was showed the relationship of CNG shortage and the factors which were affecting from this shortage in any aspect. It also showed the problems and issues that have been arisen due to this unannounced shortage. It showed that routine life of people has been effect immensely.

The economic as well as social and family life of people has been affected to an extent. It has been badly affecting the working and studying hours and also the career of students. Due to this shortage prices of commodities have been increased many folds. CNG shortage has impact on many aspects these aspects includes daily routine life of people, their performance at office and at class room.

This energy crisis has been affecting the household's wives and it increased their problems. It has been also affecting economic life of people and economic condition of country. It has lowered the per capita income of the people of Pakistan. This shortage has created transportation cost and due to this increase in transportation cost, the earnings were lowered day by day and prices of commodities were increasing day by day. The most of people of twin cities of Islamabad and Rawalpindi tended to use public transport due to huge difference between $\mathrm{CNG}$ and fuel prices. As a result of this trend the earnings of the van and taxi has been lowered.

\section{4. Model of Study}

Figure 6 showed the whole model of this qualitative study. This model was created by using NVIVO 10 as tool. In this model only those issues and problems were included which was repeated by every respondent and important in nature. In this figure all the problems and issues which were caused due to CNG shortage. In this study there were aspects which were affected by this energy crisis.

The effect of CNG shortage on daily routine life, performance, psychological factors and economic problems were also shown in figure. In the above diagram there were parent and child relation between the nodes. There were four children of CNG shortage i.e. Effect on daily routine life, economic condition, effect on performance and psychological issues raised from CNG shortage. Due to CNG shortage, working and studying hours were badly affected; social and family were affected immensely.

The productivity and efficiency of the businesses, employees and students were decreased due to this CNG shortage. Economic condition of country was also affected by this shortage because of not fulfillment of export contracts. Unemployment rate was also increased because many textile and other industries shut down their businesses due to unannounced close down of CNG. Because there was big difference between CNG and petrol prices, transportation costs increase many times and due to this price of commodities were also increased and economic life of people were going worst day by day. CNG shortage increased the issue of people i.e. increase in work load, time wastage and it was also affecting their social and family life. Some people said that keeping in line and wait for fuel, borders them. 


\section{5. Matrix Representation}

Figure 7 showed the CNG shortage and its impact on daily routine life of people. CNG shortage was on right side in this picture and all the issues which were generated due to this shortage were at the bottom of diagram. These all issues were numbered from A to T. their names were mentioned on diagram. It meant that about 20 issues were important which were caused due to CNG shortage. These were those issues which were repeated and have significant importance on life of people.

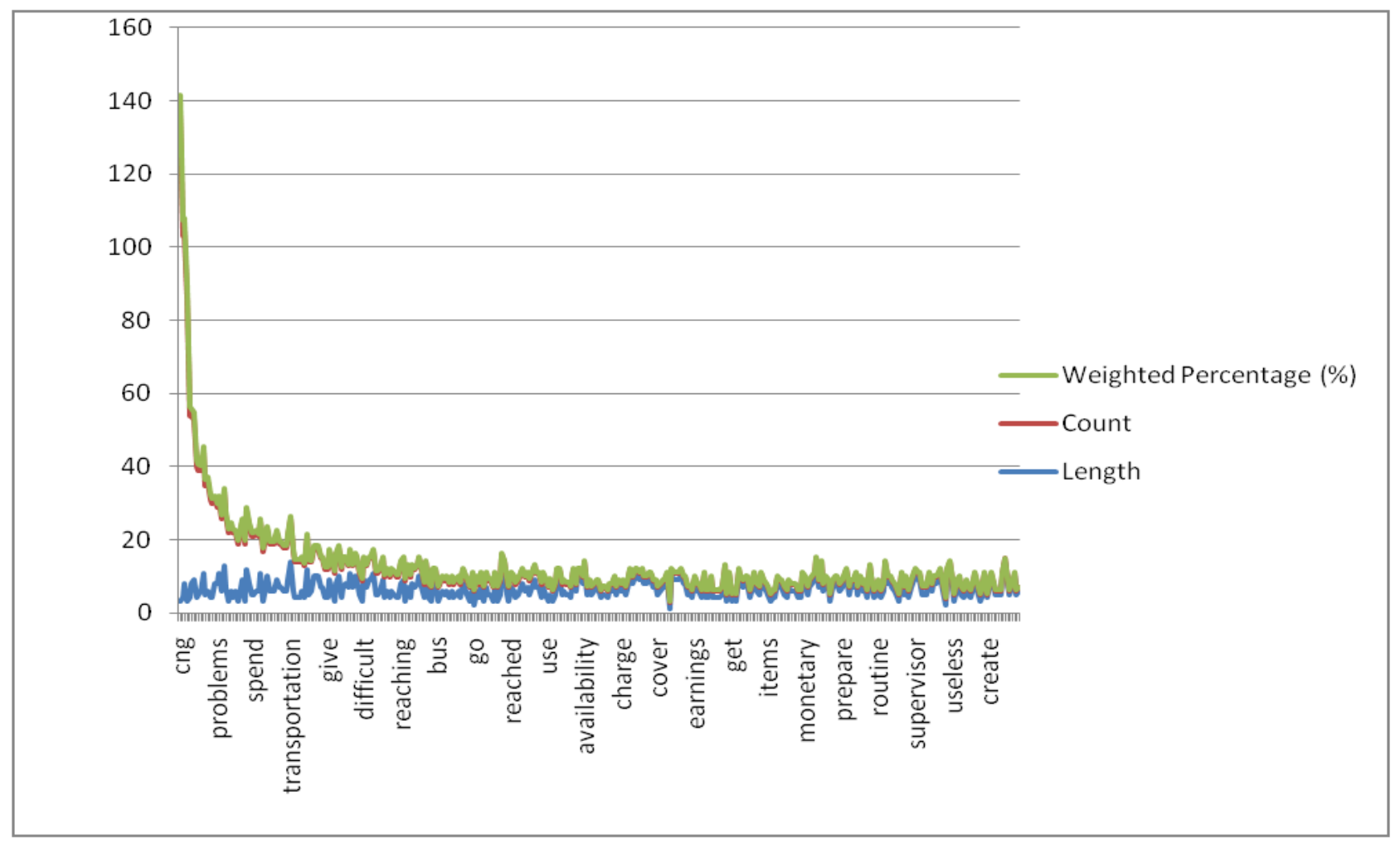

Fig. 1. Graphical representation of word frequency.

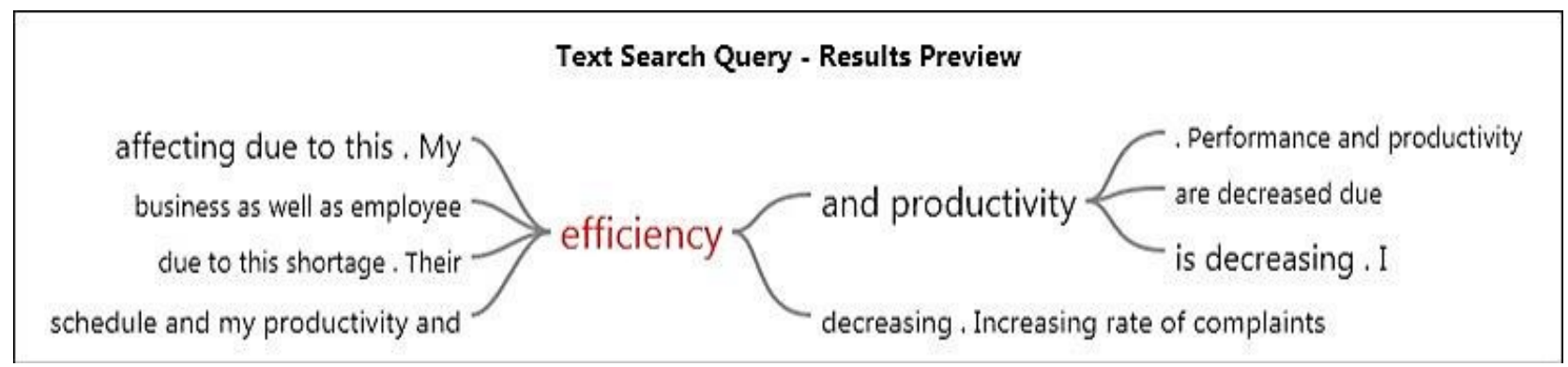

Fig. 2. Text Query for relationship of CNG and Efficiency. 


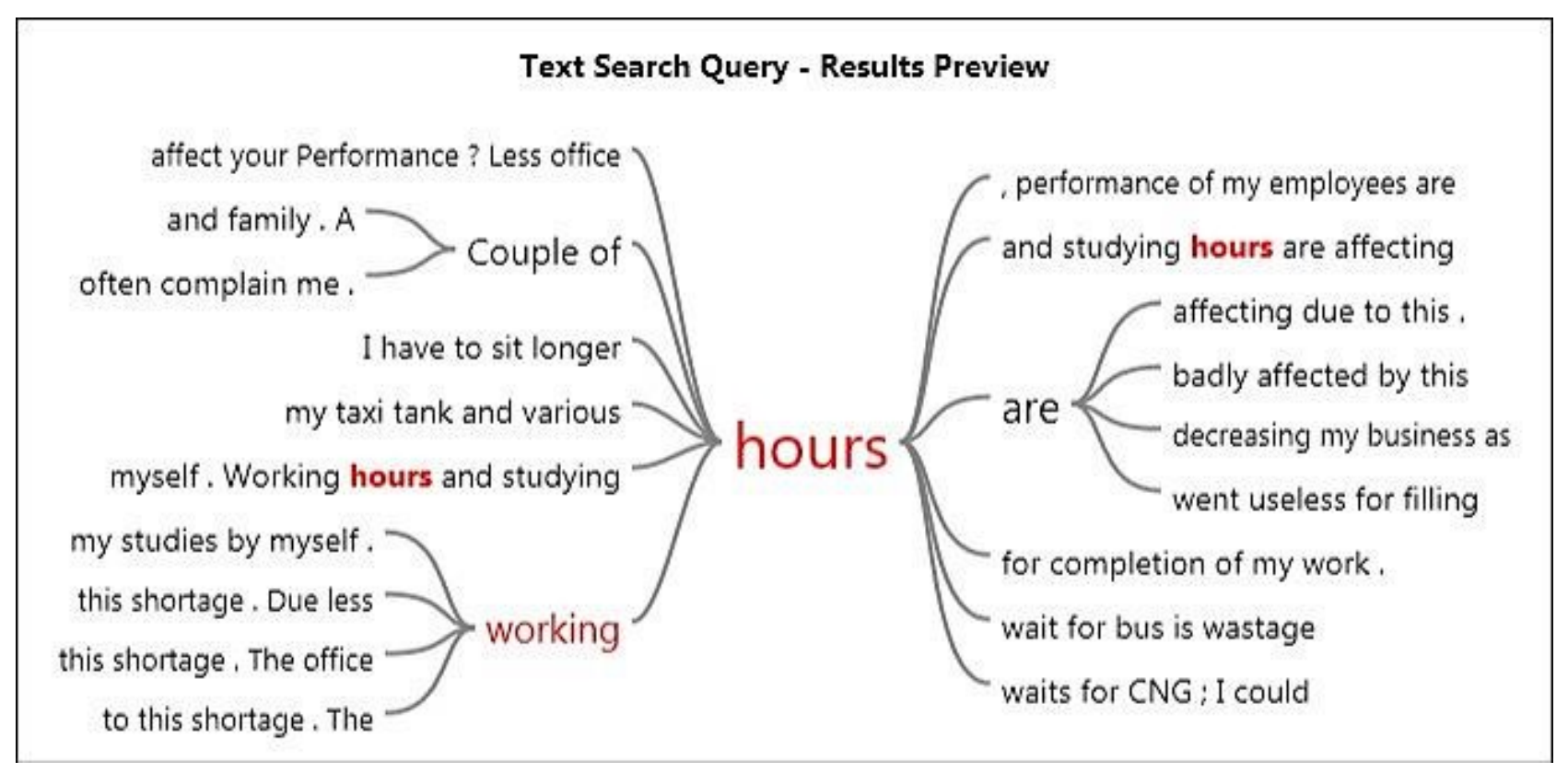

Fig. 3. Impact of CNG on working and Studying Hours.

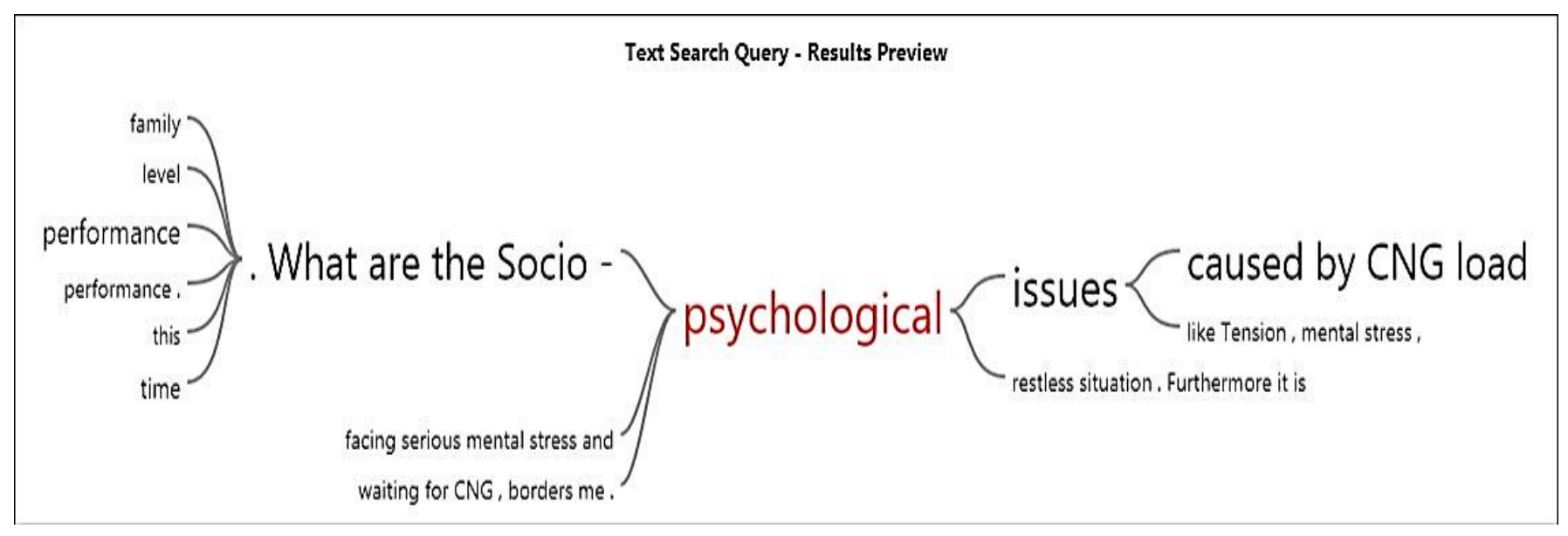

Fig. 4. Psychological Issues due to CNG shortage. 


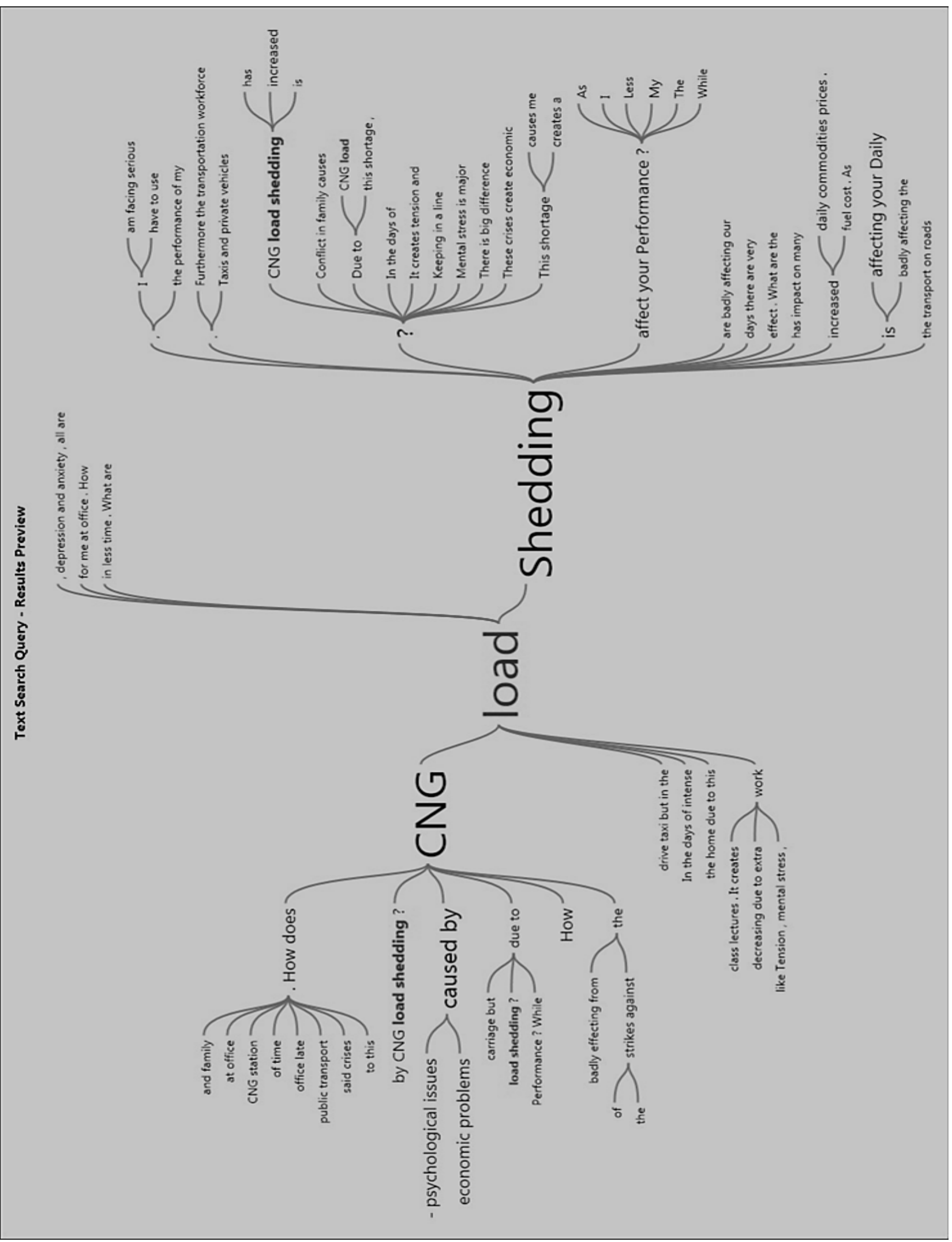

Fig. 5. Tree Map of CNG Load Shedding and its Impact on Daily routine life of People. 


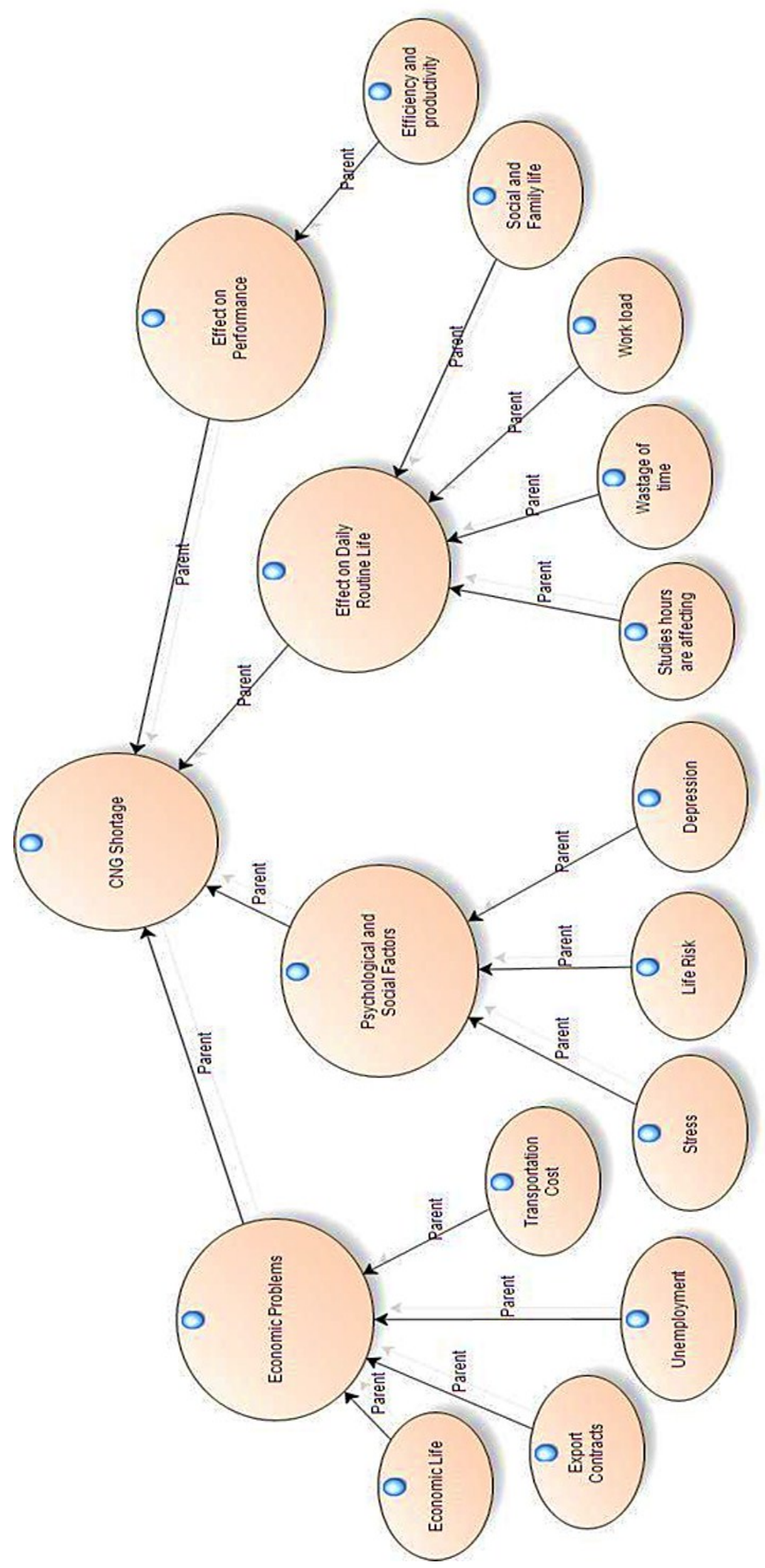

Fig. 6. Model of the Study. 


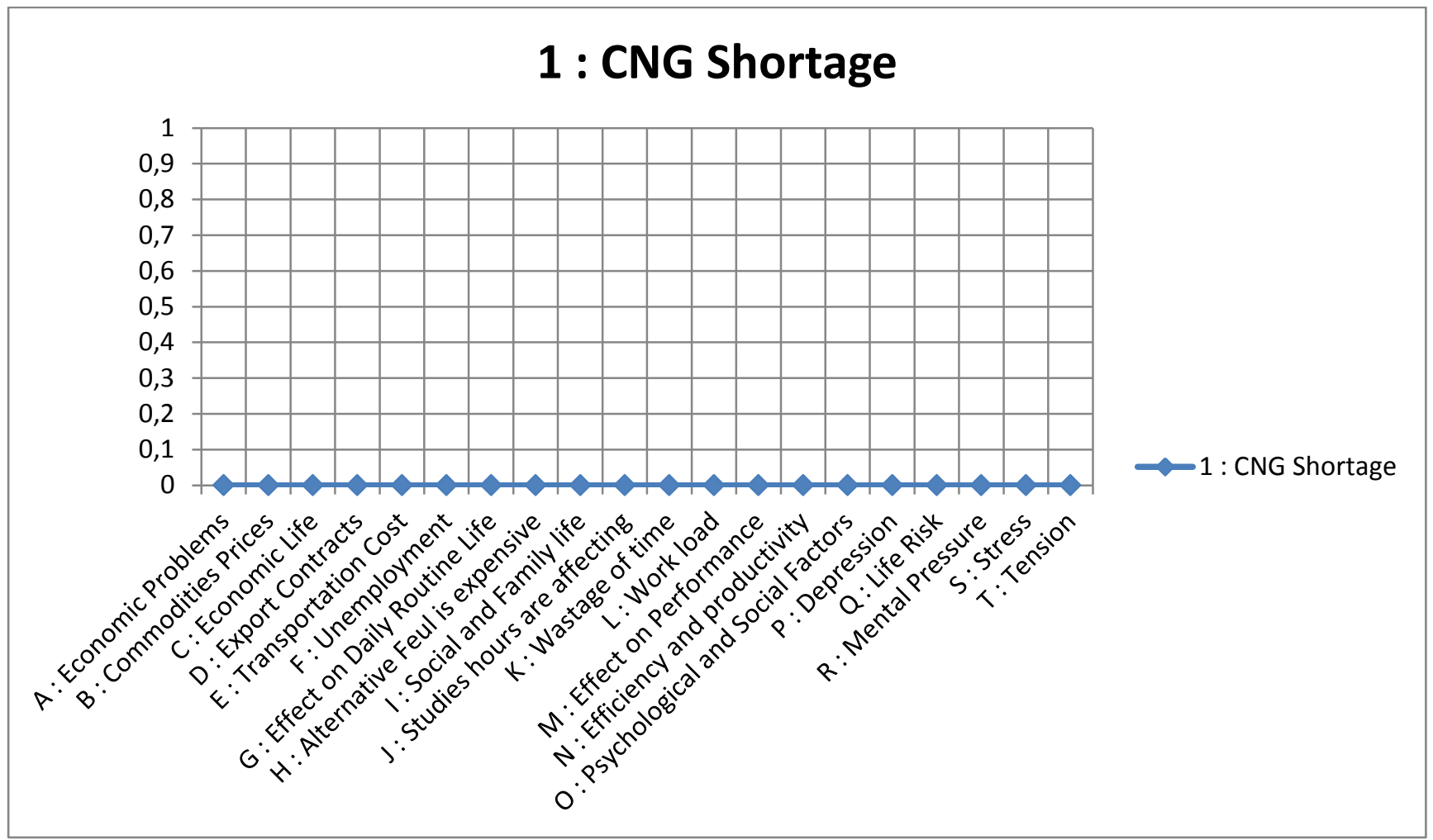

Fig. 7. Matrix Representation of CNG Shortage and Its Impact on Daily Life of People.

\section{DISCUSSION}

The findings of present study were well supported by previous studies. The data was collected from respondents at CNG stations. Interviews were conducted when people were waiting in line for many hours to fill their car gas tanks. Many researchers have conducted empirical studies on energy issues in many countries but few have considered qualitative aspect of these issues (Ahmad, 2009; Gravin, 1983; James, 1996; Rosenberg, 1983; Schurr, 1983; Yuan, 2010). Many researchers found that energy crisis has increased the economic issues in the country which was suffering from crisis (Yuan, 2010).

\section{CONCLUSION}

It was concluded from the results of this qualitative study that energy played an important role in growth and life style of people of that country. If the country was suffering from energy crisis, it creates severe issues for the life of people of that county. The result of study showed that due to $\mathrm{CNG}$ shortage the daily routine life of people were affecting immensely, their routine became disturbed, work load was increased and studying and working hours were also decreased. Performance and efficiency of industries and employees were decreased day by day. Social gathering of people was also affected due to this shortage. People reached late at night and could not spend time with their family. 


\section{Limitations}

There are few limitations of this qualitative study. The sample size was small due to time constraint. More analysis methods could be used for analysis of data like E-views and SPSS. The study could be conducted in other contexts.

\section{Recommendations}

It was recommended that the government should focus on this energy crisis. If this issue was not resolved on time it could create more severe results on economic condition and life of people. Government should make new policies about energy crisis according to need and demand of people. Government should adopt alternative energy resources to fulfill the need of society.

\section{References}

[1] Ahmad M., B. (2009). Moving towards Energy Sufficiency, Sustainability, and Sovereignty. EMR-Consult.

[2] APA. (1995), from http://apcnga.org/newsDetail.php?netwire=19 Eleventh Five Year Plan. (2010): Planning Commission of India.

[3] Gravin J., Clifton C., Journal of Business Strategy 4(2) (1983) 60-62.

[4] Harms S., Jack S., Ssebunnya J., Kizza R. (2010). The orphaning experience: descriptions from Ugandan youth who have lost parents to HIV/AIDS. Harms et al. Child and Adolescent Psychiatry and Mental Health, 4(6).

[5] Jamal J. (2012). Gas load shedding hits consumers hard. Islamabad.

[6] James C., Williams. (1996). Fuel at Last: Oil and Gas for California, 1860s-1940s. California Historical Society 75(2) 114-127.

[7] Kou B., et al., International Journal of Business and Management 4(10) (2009).

[8] Li L., International Journal of Business Management 5(3) (2010).

[9] Michael S., Geography 71(1) (1986) 65-67.

[10] Richards. (2006). Qualitative Research Design. Thinking Research.

[11] Rosenberg N. (1983). The effects of energy supply characteristics on technology and economic growth. In S. Schurr,S. Sonenblum and D.O. Wood, eds, Energy, Productivity, and Economic Growth. Cambridge University Press.

[12] Schurr S. (1983). Energy efficiency and economic efficiency: an historical perspective. In S.Schurr,S. Sonenblum,D.O. Wood, eds., Energy, Productivity, and Economic Growth. Cambridge University Press, Cambridge, Mass.

[13] Yuan M., et al. (2010). Policy Effectiveness in Energy Conservation and Emission Reduction. The Quarterly Journal of the IAEE's Energy Economics Education Foundation, 32(special).

[14] Zaid K. (2012). An Insight to Energy Crisis. Islamabad: Insaf Research Wing. 